\title{
ORIGINAL ARTICLE \\ FEELINGS OF HOPELESSNESS IN STABLE HIV-POSITIVE PATIENTS ON ANTIRETROVIRALS
}

\author{
M Y H Moosa, MMed (Psych), FCPsych \\ F Y Jeenah, MMed Psych, FCPsych \\ Department of Psychiatry, University of the Witwatersrand, Johannesburg
}

\begin{abstract}
Aim. The coping skills and styles individuals utilise to deal with the stress of HIV infection greatly influence the psychological impact of this illness and potential consequent feelings of hopelessness. The aim of this study was to describe levels of hopelessness in a group of stable, non-depressed HIV-positive patients receiving antiretroviral therapy, and factors associated with hopelessness.
\end{abstract}

Method. Thirty randomly selected non-depressed patients (according to Diagnostic and Statistical Manual of Mental Disorders, 4th edition (DSM-IV) criteria) were included in this study. Demographic and other data were obtained from all subjects, who also completed the Beck's Hopelessness Scale (BHS). The 20 true-false items of the BHS (29) measured three major aspects of hopelessness, which was interpreted on the total scale score as follows: $\leq 3$ minimal, and $>3$ significant.

Results. The study population comprised 30 patients with a mean age of 37.9 years (standard error (SE) 1.18) (range 28 - 51 years). The mean BHS score was 4.03 (SE 0.55), with a range from 0 to 12. There were no statistically significant correlations between BHS scores of the study population and gender, marital status, employment status, level of education, years since the diagnosis of HIV, or number of children $(p>0.05)$. Eighteen subjects (60\%) scored 3 or less on the BHS, considered minimal levels of hopelessness. However, $12(40 \%)$ scored more than 3 , which is considered significant; of these $23 \%$ had scores of 7 or more. There was no statistically significant association between BHS scores and gender, employment status, level of education, number of children or number of years since diagnosis $(p>0.05)$. However, patients who were married or living with partners were statistically more likely to score higher on the hopelessness scale compared with those who were single $(p<0.05)$.

Conclusion. Hopelessness is a psychological distress reaction that is common but largely undetected in stable HIV-positive patients on antiretrovirals. Feelings of hopelessness may result in increase in risk-taking behaviour (e.g. unprotected sex, drug use, sharing needles) and attempted suicide.

Coping is defined as 'the cognitive and behavioral efforts made by an individual to alter or manage the problems caused by stressful situations.' The effectiveness of coping is associated with variables such as extent of social support, ${ }^{2,3}$ personality factors such as selfesteem and control, ${ }_{1}^{4}$ and rate of occurrence of stressful events. ${ }^{5}$ Individuals with active behavioural coping strategies are likely to have fewer mood disturbances, a better quality of life ${ }^{6}$ and a reduction in risk-taking behaviour, ${ }^{7}$ whereas individuals with inadequate and avoidant coping styles are likely to have higher levels of emotional stress and increased feelings of hopelessness or negative expectations. ${ }^{3,8-11}$

The dynamics of hope are multifaceted and comprise a complex combination of 'hope', 'despair' and 'hopeless- ness.'12 With hope, the individual fights against inability to cope and has the belief that life is worth living both in the present and the future. Despair is a downward process that results in being stuck in a situation, losing grip, sinking into a narrow existence, losing perspective of the future and questioning the possibility of hope. ${ }^{13}$ Hopelessness includes helplessly giving up everything (including hope) and living in emptiness in the face of an assumed non-existent future.

Hopelessness or negative expectation is among the psychological variables that are predictive of suicide. The patient misconstrues his or her experience in a negative way and anticipates serious outcomes for his or her problems. This sense of hopelessness may lead the person to believe that suicide is the only feasible strategy 
for dealing with seemingly insoluble problems. ${ }^{14-17}$ Beck et al. ${ }^{18}$ in a 10-year prospective follow-up study of 165 patients hospitalised with suicidal ideation, confirmed that hopelessness was predictive of actual suicide.

The prevalence of HIV and AIDS in South Africa has reached pandemic proportions. Living with HIV in a country where HIV is hugely stigmatised can be extremely stressful and causes mental suffering. The poorest sectors of society are most vulnerable and the consequences for them are most severe. Loss of income, additional care-related expenses and mounting medical fees push affected households deeper into poverty. The burden of coping often rests with women, who are faced with stepping up to a role as income-earners, mothers and caregivers. HIV has resulted in disintegration of family units and households.

The effectiveness of the coping abilities and styles individuals utilise to deal with the stresses of HIV greatly influences the psychological impact of this illness. Furthermore, the presence of co-morbid personality and adjustment disorders (which have an increased prevalence in the HIV-positive population) ${ }^{19}$ also impacts on coping abilities. Persons with these disorders are more likely to cope in a dysfunctional way. ${ }^{20}$

There is evidence that hopelessness in individuals with HIV and AIDS may be associated with depression, ${ }^{21}$ which may lead to decreased adherence to medication regimes, further suppression of immunity and accelerated disease progression as well as risk of suicide. From a psychobiological perspective, active coping is associated with higher total lymphocyte, CD4 and natural killer cell counts, ${ }^{22,23}$ while a passive ${ }^{24}$ or fatalisticresigned coping style and hopelessness ${ }^{25}$ are associated with poor HIV treatment adherence and rapid progression of HIV disease, ${ }^{26}$ particularly if they are associated with depression and occurrence of severe stressful events. ${ }^{27,28}$

To measure hopelessness, Beck et al. ${ }^{29}$ developed the 20-item Beck's Hopelessness Scale (BHS), applied exploratory factor analysis and argued that the scale measures three specific components (affective, motivational and cognitive). The KR-20 coefficients (measures of the scale's internal consistency) range from 0.82 to 0.93 . In general practice, the correlation between the BHS and ratings of hopelessness was 0.74 and in suicide attempters it was 0.62. The hopelessness construct is a factor in many mental disorders and is highly correlated with measures of depression and suicidal intent and ideation. ${ }^{30}$

Much of the work on psychiatric morbidity in HIV has been done in the Western world. Despite the high prevalence of HIV in South Africa, very few studies have been published on the ability of individuals to cope with the illness. Furthermore, in South Africa HIVinfected patients may be at greater risk for psychopathology than patients in the developed world because of their potentially stressful living conditions. The aim of this report was to describe levels of hopelessness and associated factors in a group of stable, non-depressed HIV-positive patients receiving antiretroviral (ARV) therapy.

\section{METHODS}

The study was part of a larger prospective, randomised and controlled study designed to compare response to treatment, effects on immune markers and adherence to ARVs in patients with depression compared with those without depression. The sampling was a convenience sampling, as it included only patients attending the Perinatal HIV Research Unit clinic at Chris Hani Baragwanath Hospital, Johannesburg. Volunteers who were 18 years and older and medically stable and had been on antiretroviral therapy for more than 6 months were screened for possible inclusion in the study.

Thirty randomly selected non-depressed patients (according to Diagnostic and Statistical Manual of Mental Disorders, 4th edition (DSM-IV) criteria) were included in the study. Depressive symptoms were determined using the Hamilton Depression Rating Scale (HAMD) (the higher cut-off score of 14 or more was regarded as indicative of a diagnosis of depression). Additional data (age, gender, marital status, employment status, level of education, number of children, and number of years since diagnosis of HIV) were obtained from all subjects, who also completed the BHS. The 20 true-false items of the BHS29 measured three major aspects of hopelessness, which was interpreted on the total scale score as follows: $\leq 3$ minimal, and $>3$ significant.

The study was approved by the Committee for Research on Human Subjects, University of the Witwatersrand. For statistical analyses, the subjects were divided into two groups, those with a BHS score of $\leq 3$ and those with a score of $>3$. Descriptive statistics were computed as means and frequencies (count and percentages). Comparisons were made between the two groups with regard to gender, marital status, employment status, number of children, level of education and number of years since diagnosis by the use of contingency tables (chi-square test with Fischer's exact test). Logistic regression was computed to determine any significant correlations between BHS scores and exposure variables. All analysis was done using the Statistical Package for Social Sciences 10.0 for Windows (SPSS Inc., Chicago, III.). A value of $p<0.05$ was considered significant. 


\section{RESULTS}

The study population comprised 30 patients, with a mean age of 37.9 years (standard error (SE) 1.18) (range 28 - 51 years). All had acquired HIV infection through heterosexual contact and had disclosed their status to their partner or a significant member of their family. The majority of patients (63.3\%) were on a nevirapine-based first-line regimen. Adherence to medication was good, with most patients virally suppressed and with a mean CD4 count of 405.37 cells/ $\mu$ l (SE 48.26). Clinically all the patients were non-depressed, and the mean HAMD score was 2.1 (SE 1.63) with a range from 0 to 5 .

The mean BHS score was 4.03 (SE 0.55), with a range from 0 to 12 (Fig. 1).

Eighteen subjects (60\%) scored 3 or less on the BHS, considered minimal levels of hopelessness. However, 12 $(40 \%)$ scored more than 3 , which is considered significant; of these $23 \%$ had scores of 7 or more. Comparisons between these two groups with respect to some variables are listed in Table I.

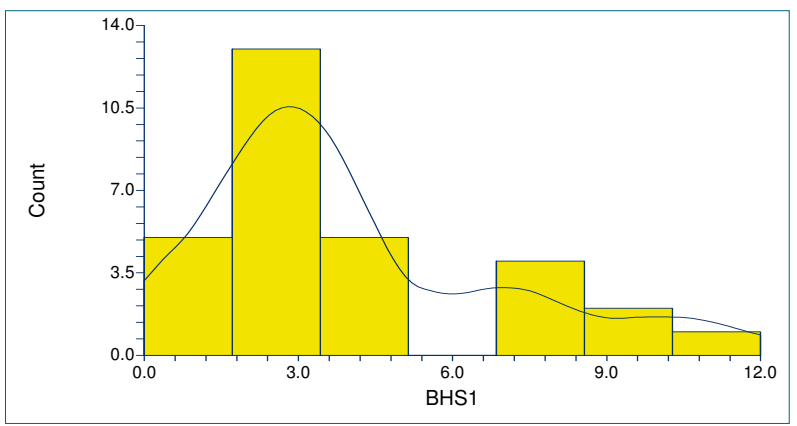

Fig. 1. Histogram of Beck's Hopelessness Scale scores.
There were no statistically significant correlations between BHS scores of the study population and gender $(r=-0.19, p=0.313)$, marital status $(r=0.33, p=0.071)$, employment status ( $r=-0.26$; $p=0.162)$, level of education $(r=-0.22 ; p=0.240)$, years since the diagnosis of HIV $(r=0.24 ; p=0.203)$, or number of children $(r=0.11$; $p=0.567)$. However, there was a trend indicating that subjects who were female, unemployed, married and/ or had more children were more likely to experience higher levels of hopelessness.

There was no statistically significant association between BHS scores and gender $(p=0.184)$, employment status ( $p=0.769)$, level of education ( $p=0.933)$, number of children $(p=0.933)$, or number of years since diagnosis ( $p=0.755)$. However, patients were who married or living with partners were statistically more likely to score higher on the hopelessness scale compared with those who were single $(p=0.019)$.

\section{DISCUSSION}

Although the sample was small, this study found that a significant proportion (40\%) of a group of HIV-positive patients had mild to moderate levels of hopelessness as measured by the BHS, despite being medically stable, adherent to their antiretroviral medication and virally suppressed, and having high CD4 counts. Similar results of 'mild' feelings of hopelessness were reported by Remien et al. ${ }^{21}$ However, nearly all their patients maintained the conviction that good times lay ahead and that their lives were worthwhile.

This finding is of relevance because there is published evidence that hopelessness may play a key role in the

TABLE I. FREOUENCY OF BECK'S HOPELESSNESS SCALE SCORES IN RELATION TO PATIENT VARIABLES

\begin{tabular}{|c|c|c|c|c|}
\hline \multirow[b]{2}{*}{ Variables } & \multirow{2}{*}{$\begin{array}{l}\text { Study population } \\
(N=30)\end{array}$} & \multicolumn{2}{|c|}{ BHS score } & \\
\hline & & $\leq 3(N=18)$ & $>3(N=12)$ & \\
\hline \multicolumn{5}{|l|}{ Gender } \\
\hline Male & $6(20 \%)$ & $2(6.7 \%)$ & $4(13.3 \%)$ & Fisher's exact \\
\hline Female & $24(80 \%)$ & $16(53.3 \%)$ & $8(26.7 \%)$ & $p=0.184$ \\
\hline \multicolumn{5}{|l|}{ Marital status } \\
\hline Single/divorced/widowed & $18(60 \%)$ & $14(46.7 \%)$ & $4(13.3 \%)$ & Fisher's exact \\
\hline Married/cohabiting & $12(40 \%)$ & $4(13.3 \%)$ & $8(26.7 \%)$ & $p=0.01912$ \\
\hline \multicolumn{5}{|l|}{ Employment status } \\
\hline Employed & $9(30 \%)$ & $5(16.7 \%)$ & $4(13.3 \%)$ & Fisher's exact \\
\hline Unemployed & $21(70 \%)$ & $13(43.3 \%)$ & $8(26.7 \%)$ & $p=0.769$ \\
\hline \multicolumn{5}{|l|}{ Level of education } \\
\hline Grade $0-7$ & $2(6.7 \%)$ & $1(3.3 \%)$ & $1(3.3 \%)$ & $\chi^{2}=0.139 ;$ df $2 ;$ \\
\hline Grade 8 - 12 & $25(83.3 \%)$ & $15(50 \%)$ & $10(33.3 \%)$ & $p=0.933$ \\
\hline Tertiary & $3(10 \%)$ & $2(6.7 \%)$ & $1(3.3 \%)$ & \\
\hline \multicolumn{5}{|l|}{ No. of years since diagnosed } \\
\hline $0-5$ & $11(36.7 \%)$ & $7(23.3 \%)$ & $4(13.3 \%)$ & Fisher's exact \\
\hline$>5$ & $19(63.3 \%)$ & $11(36.7 \%)$ & $8(26.7 \%)$ & $p=0.755$ \\
\hline \multicolumn{5}{|l|}{ No. of children } \\
\hline None & $3(10 \%)$ & $2(6.7 \%)$ & $1(6.7 \%)$ & $\chi^{2}=0.065 ;$ df $2 ;$ \\
\hline 1 & $10(33.3 \%)$ & $6(20 \%)$ & $4(20 \%)$ & $p=0.967$ \\
\hline$>1$ & $17(56.7 \%)$ & 10 (33.3\%) & $7(33.3 \%)$ & \\
\hline
\end{tabular}


prediction of suicidal behaviour. ${ }^{30} \mathrm{~A}$ high BHS score alerts the therapist to unstated or denied suicidal intentions. Remien et al. ${ }^{21}$ reported that despite 'mild' feelings of hopelessness and no current suicidal ideation, several of their patients considered suicide an option for the future should they become more impaired. In interpreting the results of the present study, hopelessness may best be construed as a risk factor. However, unlike certain other predictors of suicide, such as age, sex, or race, hopelessness is a characteristic that can be modified. Given the relatively slow natural progression of HIV infection and the increased survival made possible by recent medical therapies, there should be a focus on interventions that promote the expression of negative feelings (i.e. anger) and the development of effective coping strategies that can significantly improve psychological status ${ }^{31}$ and possibly increase survival time. ${ }^{32}$ Failure to do this may mean that HIVpositive subjects repress their feelings of anger and alleviate their discomfort by risk-taking behaviour such as unprotected sex, drug use and sharing needles. ${ }^{33}$

Like the process of learning, which involves the formation of new connections between nerve cells in the brain, psychotherapy works by changing the way the brain functions. Certain types of psychotherapy, particularly cognitive-behavioural therapy (CBT) and interpersonal therapy (IPT), can help improve coping skills. The aim of IPT is to solve problems within a brief period rather than devise lifetime solutions, and its emphasis is on restoring the patient to an adequate level of functioning rather than on personality change. ${ }^{34} \mathrm{~A}$ study by Rush et $a l^{35}$ showed that depressed patients treated with cognitive therapy showed a more rapid reduction in hopelessness scores than a comparison group of depressed patients treated with an antidepressant drug.

Although this study did not find any significant correlation between feelings of hopelessness and previously reported stressors such as unemployment, having more children to care for and lack of support, there were suggestions of a trend towards this. The small sample size and the very select sample in this study may have contributed to this finding. Contrary to Remien et al.' $\mathrm{s}^{21}$ finding that long-term survivors of HIV and AIDS were more resilient and positive in terms of their mood and outlook, our patients appeared to become more hopeless with time. It is possible that we are not only failing to identify these feelings but do not provide any psychological support for persons expressing such feelings at our ARV rollout clinics.

A possible objection to the use of the BHS in prediction of suicide is that it yields a large proportion of false positives. The almost inevitable over-inclusiveness of valid predictors of a rare phenomenon such as suicide was first demonstrated by Meehl and Rosen ${ }^{36}$ and has since been widely discussed. ${ }^{37-39}$ However, it should be noted that the connotations of the terms 'false negative' and 'false positive' may not be completely appropriate. Generally these terms are applied when a specific test is able or unable to demonstrate the presence or absence of a known disease, such as diabetes or tuberculosis. The BHS attempts to identify the potential for fatal suicide attempts and not the behaviour itself. Many persons with high scores on this scale may continue to be at risk for suicide beyond the observation period, even though they have not yet made a fatal suicide attempt

\section{CONCLUSION}

This small study suggests that hopelessness may be a common psychological distress reaction present in stable HIV-positive patients on ARVs that may go undetected. These feelings of hopelessness may result in an increase in risk-taking behaviour (e.g. unprotected sex, drug use, sharing needles) and attempted suicide. We recommend that the staff at ARV rollout clinics become aware of this possibility and use the BHS as a screening tool to identify such individuals and refer them for basic psychotherapy to improve coping skills and reduce feelings of hopelessness.

\section{REFERENCES}

1. Lazarus RS. Coping therapy and research: past, present, and future. Psychosom Med 1993; 55: 234-247

2. Pakenham KI, Dadds MR, Terry DJ. Relationships between adjustment to HIV and both social support and coping. J Consult Clin Psychol 1994; 62: 1194-1203.

3. Wolf TM, Balson PM, Morse EV, et al. Relationship of coping style to affective state and perceived social support in asymptomatic and symptomatic HIVinfected persons: implications for clinical management. J Clin Psychiatry 1991 52: 171-173.

4. Folkman S, Chesney M, Pollack L, et al. Stress, control, coping, and depressive mood in human immunodeficiency virus-positive and -negative gay men in San Francisco. J Nerv Ment Dis 1993; 181: 409-416.

5. Vedhara K, Nott KH. Psychosocial vulnerability to stress: a study of HIV-positive homosexual men. J Psychosom Res 1996; 41: 255-267.

6. Friedland J, Renwick R, McColl M. Coping and social support as determinants of quality of life in HIV/AIDS. AIDS Care 1996; 8: 15-31.

7. Martin DJ. Coping with AIDS and AIDS-risk reduction efforts among gay men AIDS Educ Prev 1993; 5: 104-120.

8. Krikorian R, Kay J, Liang WM. Emotional distress, coping, and adjustment in human immunodeficiency virus infection and acquired immune deficiency syndrome. J Nerv Ment Dis 1995; 183: 293-298.

9. Fleishman JA, Fogel B. Coping and depressive symptoms among people with AIDS Health Psychol 1994; 13: 156-169.

10. DeGenova MK, Patton DM, Jurich JA, et al. Ways of coping among HIV-infected individuals. J Soc Psychol 1994; 134: 655-663.

11. Nicholson WD, Long BC. Self-esteem, social support, internalized homophobia, and coping strategies of HIV gay men. J Consult Clin Psychol 1990; 58: 873876.

12. Kylma J, Vehvilainen-Julkunen $\mathrm{K}$, Lahdevirta J. Hope, despair and hopelessness in living with HIV/AIDS: a grounded theory study. J Adv Nurs 2001; 33: 764775.

13. Kylma J. Despair and hopelessness in the context of HIV: a meta-synthesis on qualitative research findings. J Clin Nurs 2005; 14: 813-821.

14. Beck AT, Brown G, Berchick RJ, et al. Relationship between hopelessness and ultimate suicide. Am J Psychiatry 1990; 147: 190-195.

15. Dyer JA, Kreitman N. Hopelessness, depression, and suicide intent in parasuicide. BrJ Psychiatry 1984; 144: 127-133.

16. Nekanda-Trepka CJS, Bishop S, Blackburn M. Hopelessness and depression. Br Clin Psychiatry 1983; 132: 954-956.

17. Wetzel KD, Margulies T, Davis $R_{1}$ et al. Hopelessness, depression, and suicide intent. J Clin Psychiatry 1980; 41: 159-1608.

18. Beck AT, Steer RA, Kovacs M, et al. Hopelessness and eventual suicide: a 10-year prospective study of patients hospitalized with suicidal ideation. Am J Psychiatry 1985; 142: 559-563.

19. Chuang HT, Jason GW, Pajurkova EM, et al. Psychiatric morbidity in HIV infection. Int Conf AIDS 1990; 6: 176.

20. Perkins DO, Davidson EJ, Leserman J, et al. Personality disorder in patients infected with HIV: a controlled study with implications for clinical care. Am J Psychiatry 1993; 150: 309-315.

21. Remien RH, Rabkin J, Katoff L, Williams J. Suicidality and psychological outlook 
in long term survivors of AIDS. Int Conf AIDS 1991; 7: 50.

22. Goodkin $K$, Fuchs I, Feaster D, et al. Life stressors and coping style are associated with immune measures in HIV-1 infection: A preliminary report. Int J Psychiatry Med 1992: 22: 155-172.

23. Goodkin K, Blaney NT, Feaster D, et al. Active coping style is associated with natural killer cell cytotoxicity in asymptomatic HIV-1 seropositive homosexual men. J Psychosom Res 1992; 36: 635-650.

24. Solano L, Costa M, Salvati S, et al. Psychosocial factors and clinical evolution in HIV infection: a longitudinal study. J Psychosom Res 1993; 37: 39-51.

25. Reed GM, Kemeny ME, Taylor SE, et al. Realistic acceptance as a predictor of decreased survival time in gay men with AIDS. Health Psychol 1994; 13: 299 307.

26. Kalichman SC, Rompa D. HIV treatment adherence and unprotected sex practices in people receiving antiretroviral therapy. Sexually Transmitted Infections 2003; 79; 59-61.

27. Leserman J, Petitto JM, Perkins DO, et al. Severe stress, depressive symptoms, and changes in lymphocyte subsets in human immunodeficiency virus-infected men. Arch Gen Psychiatry 1997; 54: 279-285.

28. Evans DL, Leserman J, Perkins DO, et al. Severe life stress as a predictor of early disease progression in HIV infection. Am J Psychiatry 1997; 154: 630-634.

29. Beck AT, Weissman A Lester $D$, et al. The measurement of pessimism: the hopelessness scale. J Consult Clin Psychol 1974; 42: 861-865.

30. Aish A and Wasserman D. Does Beck's Hopelessness Scale really measure severa components? Psychol Med 2001; 31(2): 367-372
31. Greer S, Moorey S, Baruch JDR, et al. Adjuvant psychological therapy for patients with cancer: a prospective randomised trial. BMJ 1992; 304: 675-680.

32. Spiegel $D$, Bloom J, Kraemer HC et al. The beneficial effect of psychosocial treatment on survival of metastatic breast cancer patients: a randomized prospective outcome study. Lancet 1989; 14: 888-891.

33. Kelly JA, Murphy DA, Bahr $R$, et al. Factors associated with severity of depression and high-risk sexual behavior among persons diagnosed with human immunodeficiency virus (HIV) infection. Health Psychol 1993; 12: 215-219.

34. Klerman GL, Weissman MM, Rounsaville BJ, et al. Interpersonal Psychotherapy of Depression. New York: Basic Books, 1984.

35. Rush AJ, Beck AT, Kovacs $M$, et al. Comparison of the effects of cognitive therapy and pharmacotherapy on hopelessness and self-concept. Am J Psychiatry 1982; 139: 862-866.

36. Meehl PE, Rosen A. Antecedent probability and the efficiency of psychometric signs, patterns, or cutting scores. Psychol Bull 1955; 52: 194-216.

37. Galen RS, Gambino SR. Beyond Normality: The Predictive Value and Efficiency of Medical Diagnoses. New York, John Wiley \&t Sons, 1975

38. Reinhardt HE. Statistical theory and clinical practice in predicting rare phenomena. Psychol Rep 1979; 45: 468-470.

39. Vanderplas JM, Vanderplas JH. Multiple- versus single-index predictors of dangerousness, suicide, and other rare behaviors. Psychol Rep 1979; 45: 343349 . 